7 years later his vision was R. 6/18, L. 6/9, but, according to my house surgeon's notes, he was smoking $1 \frac{1}{2}$ ozs. a day and drinking three pints of alcohol. So this man seems to have practically recovered without entirely giving up the poisons and to have resumed excessive use of them without suffering from it.

That patients can resume smoking without bringing on the trouble again, I know from cases that I have had in my private practice, and I believe that tobacco, as a rule, only gets its chance to cause trouble when associated with complete running down of general health, often associated with insufficient food, mental worries, or financial troubles, all tending to produce a depressed state of the body, and rendering it more liable to the action of the poison.

\title{
TRANSLATION
}

\section{THE OCULAR COMPLICATIONS OF LETHARGIC ENCEPHALITIS*}

\author{
BY \\ V. MORAX
}

IN view of the number of cases of so-called "Botulism" with ocular complications reported in this country of late years the following translation may interest readers:

At the meeting of March 22, 1918, of the Medical Society of the Paris Hospitals, Dr. Netter drew the attention of his colleagues to a peculiar nervous affection which, in addition to other disturbances, was principally characterized by a state of prolonged somnolence: whence the name "lethargic encephalitis" under which it was described by Economo in 1917. By reason of the interest and importance of the ocular complications observed in sufferers from this affection it has seemed to me useful to give a short account of the general symptoms of the disease and to enumerate the eye complications.

Netter's clinical description is as follows: "The disease, which usually runs a febrile course, begins with headache and sometimes with vomiting. Somnolence, which becomes more and more pronounced, appears rapidly. To begin with there is merely drowsiness; this is followed by true sleep from which one can awake the patient, who replies reasonably and walks without hesitation, but soon passes into slumber. At a more advanced stage

"Translated from Annales d'Oculistique, July, 1918. 
sleep may merge into coma. Sleep may be broken by delirium, trembling, and rarely by convulsions. The muscular apparatus of the eyes is almost always affected: paralysis, ptosis, nystagmus, and more rarely diplopia.

The somnolence, the headache, and the ocular symptoms naturally make one think of meningitis, cerebro-spinal or tuberculous. But the usual signs of meningitis are lacking or little marked. The meningeal line (la raie méningitique) may be readily elicited, but if pressure on the eyeballs is painful, irregularities of the pulse and of the respiration are generally missing. Rigidity of the neck and Kernig's sign are absent or poorly marked."

Fluid withdrawn by lumbar puncture is clear and contains the normal amount of albumin ; as regards the cells, enumeration shows a normal figure, 2 or 3 elements, rarely more than 7 . No kind of bacteria is found upon culture. If one is not upon one's guard one thinks of a cerebral tumour, especially of tubercle of the cerebellum. If the patient recovers this assumption may appear to be justified, but if he dies no trace of tubercle can be found. The surface and sections of the brain appear to be normal or simply injected and of reduced consistence.

The evolution of the disease is extremely variable. Among 7 patients 2 died, one in several hours and the other at the end of 17 days. Among 5 others one was cured in the course of a few days; the state of the others was indeterminate more than 3 weeks after the commencement.

Ocular symbtomatology.-The ocular manifestations which have more particularly attracted the attention of clinicians, ptosis, nystagmus, and diplopia, have been described by Dr. Netter, who found one or two of these symptoms in 5 of the 7 cases that fell under his notice. In some of the observations published since Netter's communication (see Bulletins et Mémoires de la Société médicale des hôpitaux de Paris) the ocular manifestations have been described in some detail.

In a patient of 20 years seen at the Saint-Antoine Hospital, by M. Chauffard and Mlle Bernard, the aftection began suddenly with intense headache not accompanied by vomiting. On the third day there was double ptosis and on the fifth day convulsive movements of the right arm. When she entered the hospital on the seventh day of the illness the patient was dull. She slept the greater part of the day, but when not asleep she was lucid, replying to questions put to her. She complained constantly of violent headache. The condition of the eyes was as follows: double ptosis, the appearance being a little unusual, since the patient did not attempt to compensate the ptosis by raising the eyebrows. The movements of the eyes were very limited in all directions. Abduction was less affected than the other movements. The axes of the eyes were not always 
parallel. Nystagmus was sometimes present. Pupil and fundus normal. The corneae were insensitive. Two days later the pupils were unequal, and at the same time the somnolence increased and incontinence of urine made its appearance. Death occurred on the twenty-first day of the illness and the temperature towards the end ranged from $39^{\circ} \mathrm{C}$. to $40.9^{\circ} \mathrm{C}$. Examination of the cerebrospinal fluid yielded a normal result. The autopsy showed the absence of tuberculous or other lesions; all that could be found was congestion of the meninges of the brain and of the spinal cord, and some adhesions at the level of the cerebral fissures outside the origin of the cranial nerves.

In a case reported by Lesné, the patient, a woman of 38 years, came to the hospital in a marked condition of torpor and prostration. There was double ptosis, but no paralysis or nystagmus, and neither pupillary disturbances nor lesions of the fundus of the eye. The temperature oscillated between $38^{\circ} \mathrm{C}$. and $39^{\circ} \mathrm{C}$. The cerebrospinal fluid was normal. In three weeks the temperature became normal, the ptosis disappeared, and no traces of the disease remained.

In one of the little patients observed by Netter, whom he got me to examine, the somnolence had commenced with fever at the end of February. The mother told us that at the commencement the right eye danced, then the eyes deviated towards the left and nystagmus appeared. She remained asleep for almost four weeks. An examination of the eyes made on April 17, about six weeks after the beginning, still showed peculiar visual disturbances, including a partial paresis of the right third pair producing slight mydriasis and crossed diplopia. The pupillary reflexes to light were normal. There were no lesions of the fundus of the eye. The vision was normal in each eye, but the patient, aged 10 years, could read only with her grandmother's spectacles. This was because there was bilateral paralysis of accommodation, and I found in her a dissociation between the ciliary muscle and the sphincter of the iris, such as may be observed in the intoxication of diphtheria or botulism. There was neither ptosis nor nystagmus.

In Dr. Sainton's patient, whom he asked me to examine, I found the following several weeks after the commencement of the disease :

Pupils equal and reacting normally to light and to convergence. No lesions of the fundus of the eye. Sight normal after correction of a slight myopia. No paralysis of accommodation. Very pronounced disturbance in the mobility of the eyes with paradoxical diplopia. In the right half of the visual field the diplopia was crossed; in the left half of the field the diplopia was homonymous, the separation of the images remaining the same in the different directions. This diplopia could not be assigned to an affection of such or such a muscle or neuro-muscular group. It indicated a 
partial seizure of the sixth and of the third pair. Some slight nystagmic twitches were noticed during movements of the eyeballs.

Only in two cases connected with lethargic encephalitis, those of Claude and of Sainton, ocular symptoms were wholly absent, so much so that the question arises whether despite the absence of eye symptoms and the existence of somnolence, fever, etc., it was legitimate to connect those cases with lethargic encephalitis.

Looking at the matter from the ophthalmological point of view alone, lethargic encephalitis gives rise only to motor disturbances. The third and the sixth pairs appear to be principally affected, but in an incomplete manner. It is not a complete paralysis limited to one oculo-motor nerve, such as is often observed in endocranial syphilis. The disturbances are often bilateral.

In one observation related by Lortat-Jacob and Hallez and connected with lethargic encephalitis we have made observations which do not agree with those noted above. The patient, a woman of 49 years, had complained for a week of fatigue, of heaviness of the eyelids, and of a desire to sleep. Three weeks before she had suffered from headache day and night. During the first days she was in hospital the temperature had ranged from $37^{\circ} \mathrm{C}$. to $38.5^{\circ} \mathrm{C}$. There were bilateral ptosis and nystagmus when the eyes were turned to the right. Bilateral papillary stasis. Marked pupillary inequality, with the Argyll Robertson sign. R.V.-6 D. 3/10 ; L.V. -8 D. 5/10. Diplopia and nystagmus no longer present. The Wassermann reaction was partially positive as regards the blood, and positive as regards the cerebro-spinal fluid. After two lumbar punctures and mercurial treatment a new ophthalmological examination, made 28 days after the first, showed still a little prominence of the optic discs without venous stasis and persistance of the pupillary disturbances: inequality and Argyll Robertson sign. Lortat-Jacob and Hallez discuss the diagnosis and despite the above-mentioned facts believe it to be a case of lethargic encephalitis. This conclusion appears to me disputable in the presence of numerous signs that tell in favour of syphilis: pupillary disturbances; papillary oedema; ' and the positive Wassermann.

Papillary oedema is, in fact, the index of an alteration of the cerebro-spinal fluid. In all the other cases of lethargic encephalitis has not one insisted upon the absence of any modification of this fluid as well as upon the absence of lesions of the fundus of the eye which are the corollary of such modifications? Before the case of Lortat-Jacob and Hallez can be classed as one of encephalitis we need new observations showing that in the absence of a positive Wassermann reaction papillary oedema may exist at the same time as other symptoms of lethargic encephalitis.

Pathological Anatomy.-Examination of the cerebro-spinal fluid has not disclosed the histological and chemical modifications 
characteristic of acute or chronic inflammation of the meninges. That is an important point, from which clinical work is able to draw precise conclusions. Lymphocytosis is little marked since in the various observations that have been made with regard to that point, one has scarcely numbered more than three to ten lymphocytes in the field. The quantity of albumin contained in the cerebrospinal fluid has hardly risen above 30 centigrammes.

As to the lesions found after death they have been studied by P. Marie and Trétiakoff in a couple of cases observed by M. Chauffard and M. Bernard. The first case is particularly interesting since the ocular complications presented by the patient disclosed the typical symptomatology. The naked eye examination showed no lesion; the nervous centres appeared free from change. But the histological examination showed, on the contrary, grave changes of the grey substance of certain regions, in particular of the cerebral peduncles. After staining of sections with haematoxylin and eosin, even a low magnification showed "that each vessel of the peduncular region was surrounded by a thick muff (manchon) formed of various kinds of inflammatory elements. Some of the vessels had ruptured and given place to small haemorrhages. The parenchyma even was, as if it were, ploughed up (labouré) by the same elements, which sometimes infiltrated the tissues diffusely and sometimes formed small infective nodules. Oedema was little marked. By staining with Sudan one brings into evidence many myelophages in the perivascular spaces or even in the interior of the inflammatory nodules. As to the nervous elements, properly so-called, when stained by Bielschowsky's method they present grave alterations, particularly easy to study in the region of the locus niger where the cellular lesions attain their maximum of gravity."

These cellular lesions consist of modifications of pigmentation and of the colourability of the nuclei, retraction of the fibrillary substance and hyaline degeneration. The several modifications are found in different degrees. The axis cylinders in the neighbourhood of these cells also show some lesions: varicosities, fusiform swellings, and thickening.*

The cerebral peduncles outside the locus niger present a very pronounced inflammatory infiltration of all the periventricular grey substance, particularly marked around the nuclei of the third pair. All the same, a sufficiently large number of the nervous cells remain intact.

The fibres of the roots of the third pair in their intrapeduncular course show early Wallerian degeneration. As to the white substance of the cerebral peduncles, inflammatory phenomena are

\footnotetext{
* We are not told whether the cerebral tissues were fixed after death by the injection into the rachidian canal of fixing fluid. The autopsy having been made 36 hours after death, some reserve must be made as regards the absolute character of these cellular changes.
} 
reduced to a few perivascular muffs (manchons), without diffuse infiltration of the tissues.

The nuclei of the fifth, sixth, and seventh pairs with the motor nucleus of the trigeminal are clearly aftected, with, in places, degeneration of a large number of nerve cells.

"In brief, it concerns a focus of acute encephalitis, localized at the level of the grey substance, particularly of the isthmus of the encephalon. This encephalitis appears to us sensibly comparable with Wernicke's haemorrhagic polio-encephalitis superior."

Under the name of acute haemorrhagic polio-encephalitis superior, Wernicke described an anatomico-clinical syndrome observed by him in alcoholics, which cannot be identified with lethargic encephalitis except by the localization and the naked eye appearance of the lesions. He insisted upon the absence of fever. The aftection begins by somnolence and delirium. While these symptoms become worse, headaches and vomiting may be added to them. Paralysis of the muscles of the eye, external and internal, may appear. We often find at the same time a slight optic neuritis with retinal hæmorrhages, or a discolouration of the outer segment of the papilla as a sign of anterior alcoholic amblyopia. Wernicke noted the integrity of the sphincter of the iris and of the levator, although in his later observations he found bilateral ptosis in half the cases.

Geographical distribution.-The first cases of the affection were observed in Vienna in the first half of the year 1917. The attention of clinicians was almost simultaneously drawn in March, 1918, both in France and in England, to cases of this disease. Hall met with eleven cases in Sheffield, in the North, and in Derbyshire; Wilfred Harris had seven cases in London. The description of these cases is quite like that given by Netter, Chauffard and others of their observations. All the patients described by Harris and Hall presented ophthalmoplegia, ptosis, diplopia, nystagmus, disturbances of accommodation, and somnolence. A fact mentioned by the French and English authors is interesting, namely, that more than one case from the same house was not met with.

Aetiology.-The aetiological researches made hitherto have not allowed us to determine the cause of the disease. The analogy of certain ocular symptoms, as paralysis of accommodation and oculo-motor disturbance, with those which have been observed in botulism, has given rise to the hypothesis of an alimentary intoxication, but it does not seem that it can be accorded any probability.

Prognosis,--The prognosis as regards life of lethargic encephalitis appears to be sufficiently grave, and a fatal termination comes about more or less rapidly in a third of the cases. In other observations the disturbances have slowly disappeared, and we have seen that in several patients restitutio ad integrum has followed 
serious functional symptoms. It is still too early to determine the average duration of the different ocular manifestations.

\section{BIBLIOGRAPHY}

Von Economo.-Encephalitis lethargica. Wiener klin. Wochenschr., May Io, I9I7. R. von Wiemer.-Die Aetiologie der Encephalitis lethargica. Wiener klin. W'ochenschr., July 26, I917.

A. Netter.-Sur quelques cas d'encéphalite léthargique observés récemment à Paris. B. et M. de la Soc. méd. des hôp. de Paris, 1918, p. 307.

A. Chauffard et Mlle Bernard.-Encéphalite léthargique. Ibid., 1918, p. 330.

H. Claude.-A propos de l'encéphalite léthargique. Ibid., I918, p. 364 .

A. Netter._Existence de l'encéphalite léthargique en Angleterre. Ibid., I9I8. p. 384 .

P. Sainton.-Encéphalite léthargique. Ibid, 1918, p. 407.

Encéphalite léthargique à forme subaiguë. Ibid., 1918, p. 543.

Lortat-Jacob et Hallez. - Un cas d'encéphalite léthargique. Ibid., I918, p. 439.

Alfred Khoury.-Note sur un cas d'encéphalite léthargique. Ibid., May I7, I918, p. 455 .

De Saint-Martin et Lhermitte. - La polimésondocéphalite avec narcolepsie. Ibid., p. 457 .

A. Chauffard et Mlle. M. Bernard.-Deux cas d'encéphalite léthargique. Ibid.,

P. Marie et Trétiakoff.-Examen histologique des centres nerveux dans deux cas d'encéphalite léthargique. Ibid., p. 475.

Wernicke.-Lehrbuch der Gehirnkrankheiten, II, 229.

Ardin Delteil. - Un cas d'encéphalite léthargique observé à Alger. $B$. et $M$. de la Soc. méd. des hôp. de Paris, 1918, p. 577.

S. S.

\section{ANNOTATION}

\section{Medical Education in England}

Everyone interested in medical education should read, mark, learn, and inwardly digest the admirable and most timely notes on the subject which Sir George Newman has written in the form of a memorandum addressed to the President of the Board of Education. ${ }^{*}$ It may be mentioned at once that there is not much about ophthalmology in them, but the ophthalmologist will find ample food for thought. He will see his speciality in its proper perspective as an item in the medical student's curriculum; he will have impressed upon him the great importance of anatomy, physiology, and pathology as the only sound basis of all clinical studies, including his own; and he will be inspired to take a more active part in attacking those vast problems of ophthalmology upon which stress has been laid before in these Annotations, and which

* "Some Notes on Medical Education in England." By Sir George Newman, K.C.B., M.D., F.R.C.P., Chief Medical Officer and a Principal Assistant Secretary to the Board of Education. Cd. 9124. Price, 9d. net. His Majesty's Stationery Office. 